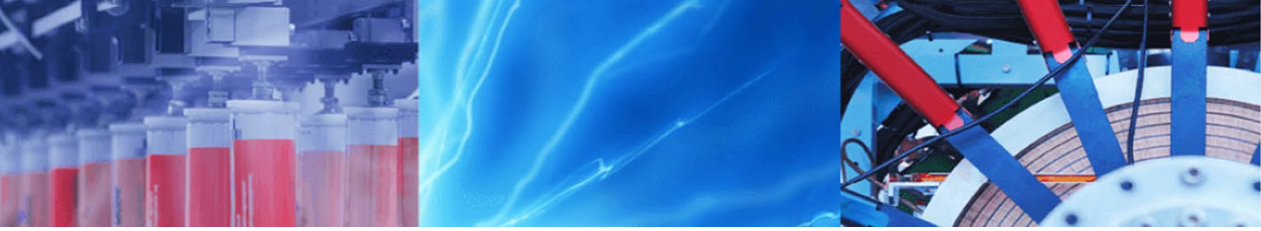

Research Article

\title{
Toxicity of gold nanoparticles in a commercial dietary supplement drink on connective tissue fibroblast cells
}

\author{
Sunisa Chaicherd ${ }^{1} \cdot$ Murray C. Killingsworth ${ }^{2,3} \cdot$ Dakrong Pissuwan $^{4,5,6,7}$ (D)
}

(c) Springer Nature Switzerland AG 2019

\begin{abstract}
Due to an increased use of gold nanoparticles (AuNPs) in various consumer products we aimed to investigate the cytotoxic impact of AuNPs found in a commercial dietary supplement drink (SD-AuNPs). The cytotoxic impact of SD-AuNPs was determined in mouse connective tissue fibroblasts (L929). The cells were treated with different concentrations of SD-AuNPs $(0.2,0.5,10,20,30,40$, and $50 \mu \mathrm{g} / \mathrm{mL})$. The results indicated that the toxicological effect of SD-AuNPs on L929 cells occurred in a dose-dependent manner. Significant reduction of cell viability was found in $\mathrm{L} 929$ cells treated with $10,20,30,40$, and $50 \mu \mathrm{g} / \mathrm{mL}$ SD-AuNPs for $24 \mathrm{~h}$. L929 cells treated with 40 and $50 \mu \mathrm{g} / \mathrm{mL}$ SD-AuNPs produced significant intracellular reactive oxygen species and TNF-a. High levels of intracellular uptake of these compounds were also observed in L929 cells treated with $50 \mu \mathrm{g} / \mathrm{mL}$ SD-AuNPs.
\end{abstract}

Keywords Gold nanoparticles - Commercial dietary supplement · ROS generation · Inflammation - Connective tissue fibroblasts

\section{Introduction}

Gold nanoparticles (AuNPs) have been of interest in biomedical applications [1-4]. Furthermore, they have been included in consumer food and drink products [4]. Accordingly, direct exposure of humans to AuNPs through ingestion, inhalation, and skin contact has increased. Although many reports have shown that AuNPs have less toxicity than other types of metal-based nanoparticles, their prevalent use makes it still of importance to evaluate the effect of AuNPs contained in consumer products. The intensive use of AuNPs in daily life can lead to more chances of exposure of the human body to these nanoparticles. Several investigations on the toxic effects of synthesized AuNPs, both from academic research laboratories and commercial sources, have been reported [5-7]. Recently, there have been many commercial dietary supplement drinks on the market that contain AuNPs (SD-AuNPs). These companies claim that addition of AuNPs into dietary supplement drinks provides health benefits, including acting as an antiinflammatory agent, and can lead to mood enhancement, and improvements in cognitive function [8]. Therefore, these products can be officially labeled as dietary supplement drinks. However, the addition of AuNPs into these dietary supplement drinks increases the direct exposure of the human body to AuNPs. Most products that contain

Electronic supplementary material The online version of this article (https://doi.org/10.1007/s42452-019-0354-2) contains supplementary material, which is available to authorized users.

Dakrong Pissuwan, dakrong.pis@mahidol.ac.th| ${ }^{1}$ Toxicology Program, Faculty of Science, Mahidol University, Bangkok 10400 , Thailand. ${ }^{2}$ Electron Microscopy Laboratory, New South Wales Health Pathology, Sydney, NSW 1871, Australia. ${ }^{3}$ Ingham Institute for Applied Medical Research, University of New South Wales, Sydney, NSW 1871, Australia. ${ }^{4}$ Materials Science and Engineering Program, Faculty of Science, Mahidol University, Bangkok 10400, Thailand. ${ }^{5}$ Capability Building Unit for Nanoscience and Nanotechnology, Faculty of Science, Mahidol University, Bangkok 10400, Thailand. ${ }^{6}$ Center of Excellent on Environmental Health and Toxicology, Faculty of Science, Mahidol University, Bangkok 10400, Thailand. ${ }^{7}$ Nanobiotechnology and Nanobiomaterials Research Laboratory, School of Materials Science and Innovation, Faculty of Science, Mahidol University, Bangkok 10400, Thailand.

SN Applied Sciences (2019) 1:336| https://doi.org/10.1007/s42452-019-0354-2 
nanoparticles do not provide detailed information on the prepared nanoparticles used in the products. This issue has led to a growing concern for human health because any risk posed by those nanoparticles is unknown. Especially based on our available knowledge, the information of cytotoxic investigation of AuNPs contained in dietary supplement drinks is very rare. Due to this reason, we were interested in testing whether SD-AuNPs could have an impact on cellular activities. To perform these studies, we used connective tissue fibroblast cells (L929) as test cells in our study. The reason that we focused on this type of fibroblast cells is because they are the predominantly common cells in connective tissue, which is the most abundant tissue in the body. Fibroblast cells play a major role in building to the extracellular matrix to support and maintain tissue structures including oral cavity and intestine. When nanomaterials containing in the drink are consumed, both oral and intestinal absorption of nanomaterials by fibroblasts can occur. Furthermore, L929 cells have been widely used in a standardized nanotoxicity test [9-12]. Thus, we used L929 cells to explore the toxicity of SD-AuNPs. It should be emphasized that we separated SDAuNPs out from a dietary supplement drinks through centrifugation, characterized their properties, and then used them for cytotoxicity assessment. A commercial dietary supplement drink with a claim of containing AuNPs was used in this work. We investigated how SD-AuNPs impact the cell viability, reactive oxygen species (ROS) generation, and the inflammatory responses of $\mathrm{L} 929$ fibroblasts. Cellular uptake of SD-AuNPs was also investigated to provide more information on the relationship between the amount of AuNPs taken up by fibroblasts and cytotoxicity. A study of cellular response to SD-AuNPs was also included.

\section{Materials and methods}

\subsection{Characterization of SD-AuNPs from a representative dietary supplement drink}

The size of SD-AuNPs contained in a representative dietary supplement drink was characterized by using transmission electron microscopy (TEM; TECNAI 20 TWIN, USA). To separate SD-AuNPs from the drink, $1 \mathrm{~mL}$ of drink was centrifuged at $9,391 \mathrm{~g}$ for $15 \mathrm{~min}$ to pellet SD-AuNPs. The SD-GNP pellet was then dispersed in Milli-Q water and the suspension was applied to a copper grid coated with formvar film and dried for TEM analysis. Light absorption of SD-AuNPs was also measured using UV-vis spectroscopy (Shimadzu UV-2550, Japan). The zeta potential and hydrodynamic diameter of the SD-AuNPs were measured by using dynamic light scattering (DLS, Zetasizer, Malvern, UK). The SD-AuNPs were dispersed in Milli-Q water or in cell culture media to check whether the cell culture media has any impact on light absorption, zeta potential, and hydrodynamic size of SD-AuNPs. The SD-AuNPs used in this work is a commercial product purchased from Japan. Based on product information, the surface of SD-AuNPs in the test drink was stabilized with carboxymethyl cellulose (CMC). Other ingredients are water and minerals (sodium, potassium, calcium, and magnesium).

\subsection{Cell culture}

L929 cells (Riken Cell Bank) were cultured in RPM 1640 medium supplemented with $10 \%$ FBS plus $1 \%$ penicillin-streptomycin. Cells were maintained in a $5 \% \mathrm{CO}_{2}$ humidified incubator at $37^{\circ} \mathrm{C}$.

\subsection{Measurement of SD-AuNPs gold concentration by inductively coupled plasma mass spectrometry (ICP-MS)}

The gold concentration in the SD-AuNPs was investigated using ICP-MS (Agilent Technologies, USA). A $4.5 \mathrm{~mL}$ of SDAuNPs diluted in Milli-Q water $(100 \times)$ was mixed with a $250 \mu \mathrm{L}$ of $65 \% \mathrm{HNO}_{3}$ and a $250 \mu \mathrm{L}$ of $37 \% \mathrm{HCl}$. The mixed solution was heated using a block heater at $100{ }^{\circ} \mathrm{C}$ for $5 \mathrm{~h}$, and ICP-MS measurements were performed. A solution of $\mathrm{Au}$ (III) at concentrations of $0,5,10,20,50,100$, and $200 \mathrm{ppb}$ was prepared for making a linear calibration curve. Optimization of rf power, nebulizer gas flow, auxiliary gas flow, and plasma gas flow was performed before the measurement.

\subsection{Cell viability assay}

A cell viability measurement was performed by seeding L929 cells at a density of $1 \times 10^{4}$ cells/well into a 96-well plate and culturing in RPMI 1640 supplemented with $10 \%$ FBS and $1 \%$ antibiotic solution for $24 \mathrm{~h}$ at $37^{\circ} \mathrm{C}$. After culturing, various concentrations of SD-AuNPs $(0.2,0.5,10$, $20,30,40$, and $50 \mu \mathrm{g} / \mathrm{mL}$ ) in fresh cell culture media were applied to the cells for $24 \mathrm{~h}$. $L 929$ cells in media were used as control. L929 cells exposed to $1 \mu \mathrm{g} / \mathrm{mL}$ of lipopolysaccharide (LPS from Escherichia coli; 0111:B4, Sigma) were under the same conditions as the positive control. After treatment, cells were washed twice with a serum-free medium, and the viability was measured using a CellTiterGlo assay (Promega) following the protocol provided by the manufacturer. Luminescence signals were collected using a microplate reader (SpectraMax ${ }^{\otimes}$ M3, USA). The relative cell viability was calculated by comparing the luminescent signal of the treated cells with those of the untreated cells. 


\subsection{ROS generation detection}

L929 cells $\left(1 \times 10^{4}\right.$ cells/well) were seeded into a 96-well plate. After incubation for $24 \mathrm{~h}$ the cells were exposed to various concentrations of SD-AuNPs (from 0.2 to $50 \mu \mathrm{g} / \mathrm{mL}$ ) for $3 \mathrm{~h}$ at $37^{\circ} \mathrm{C}$. Cells treated with $\mathrm{H}_{2} \mathrm{O}_{2}$ were also prepared as a positive control. The treated condition was performed in RPMI 1640 supplemented with 10\% FBS and 1\% antibiotic solution. The cells were washed twice with a serumfree medium and treated with $10 \mu \mathrm{M}$ dichloro-dihydrofluorescein diacetate (DCFH-DA, Sigma) for $30 \mathrm{~min}$. After treatment, the DCFH-DA was removed and the cells were washed twice with cold PBS before lysing with $20 \%$ Tween20 (in PBS w/o Ca ${ }^{2+}$ and $\mathrm{Mg}^{2+}$ ). During the lysing process, cells were shaken for $30 \mathrm{~min}$. The fluorescence signals were measured at $492 \mathrm{~nm}$ and $595 \mathrm{~nm}$ using a microplate reader.

\subsection{Pro-inflammatory cytokine measurement}

L929 cells $\left(1 \times 10^{4}\right.$ cells/well) were exposed to SD-AuNPs at concentrations of $0.2,0.5,10,20,30,40$, and $50 \mu \mathrm{g} / \mathrm{mL}$ for $24 \mathrm{~h}$. After exposure, the cell culture media were collected and centrifuged at $9,391 \mathrm{~g}$ for $15 \mathrm{~min}$ to remove SD-AuNPs remaining in the cell culture media (RPMI 1640 supplemented with $10 \%$ FBS and $1 \%$ antibiotic solution). Thereafter, the supernatant of each treatment was stored at $-80^{\circ} \mathrm{C}$ and used for determining inflammatory cytokine production (Interleukin-1 beta (IL-1 $\beta$ ); Interleukin-6 (IL-6); and Tumor necrosis factor (TNF-a)) using an enzymelinked immunosorbent assay (ELISA) kit (Biolegend). This assay was performed by following the instructions from the manufacturer.

\subsection{Cellular uptake of SD-AuNPs and localization of SD-AuNPs in L929 cells}

The cellular uptake of SD-AuNPs by L929 cells was investigated using ICP-MS (PerkinElmer, USA). The measurement was done by following the protocol published by Kim et al. [13]. L929 cells were seeded onto a 24-well plate at a density of $2 \times 10^{4}$ cells/well and incubated for $24 \mathrm{~h}$ at $37^{\circ} \mathrm{C}$ in a $5 \% \mathrm{CO}_{2}$ incubator. Cells were then cultured with RPMI-1640 medium plus $10 \%$ FBS containing SD-AuNPs at 0.2 and $50 \mu \mathrm{g} / \mathrm{mL}$ for $24 \mathrm{~h}$. After the incubation, cells were washed three times with PBS and then lysed by addition of $20 \%$ Tween-20 in PBS and sonicated for $30 \mathrm{~min}$. The cell lysate was digested overnight by addition of $250 \mu \mathrm{L}$ of digestion buffer ( $3 \mathrm{~mL}$ of $\mathrm{HNO}_{3}$ and $1 \mathrm{~mL}$ of $\mathrm{H}_{2} \mathrm{O}_{2}$ ). Next, a $3 \mathrm{~mL}$ of aqua regia $\left(\mathrm{HCl}: \mathrm{HNO}_{3}=3: 1\right)$ was added into the samples and incubated for $2 \mathrm{~h}$. After incubation, the samples were diluted, and the final samples contained $5 \%$ aqua regia. A gold standard solution $(\mathrm{Au}(\mathrm{III}))$ at concentrations of $0,0.2,0.5$, $1.0,2.0,5.0,10$, and 20 ppb was prepared to make a calibration curve used for determining the amount of gold taken up by the cells. The operating conditions of the ICP-MS were also set before measuring the gold content.

The localization of SD-AuNPs inside cells was investigated by using TEM. L929 cells at a density of $1 \times 10^{5}$ cells/ $\mathrm{mL}$ were cultured in a cell culture dish containing a glass cover slip for $24 \mathrm{~h}$. Following incubation, cells were treated with 0.2 and $50 \mu \mathrm{g} / \mathrm{mL}$ SD-AuNPs for $24 \mathrm{~h}$. Cells were then washed with $0.1 \mathrm{M}$ sodium cacodylate buffer (SCB). After washing, cells were pre-fixed with $2.5 \%$ glutaraldehyde dissolved in 0.1 M SCB. The pre-fixed cell samples were stored at $4{ }^{\circ} \mathrm{C}$ overnight. Next, cells were washed with $0.1 \mathrm{M} \mathrm{SCB}$ three times and then the cells were post-fixed with $1 \%$ osmium tetroxide $\left(\mathrm{OsO}_{4}\right)$ dissolved in $0.2 \mathrm{M} \mathrm{SCB}$ at $4^{\circ} \mathrm{C}$ for $1 \mathrm{~h}$. Cells were washed again after fixing by using the same washing process mentioned previously. Following this, cells were dehydrated by performing a sequential treatment with serial dilutions of ethanol at different concentrations (30\%, 50\%, 70\%, 80\%, 90\%, and 95\%) for $15 \mathrm{~min}$ (at each concentration) at $4{ }^{\circ} \mathrm{C} .100 \%$ ethanol was added to the cells and soaked for $15 \mathrm{~min}$ at $4{ }^{\circ} \mathrm{C}$. This was repeated 4 times in total. Following this soaking step, the embedding process was done. With this process, a mixture of propylene oxide and $100 \%$ ethanol at a ratio of 1:1 was added to cells, incubated for $15 \mathrm{~min}$ at room temperature, and then decanted. Mixtures of propylene oxide and araldite resin at ratios of 3:1, 1:1, and 1:3 were then prepared at room temperature. A 3:1 propylene oxide/araldite resin mixture was added to the cells and incubated for $1 \mathrm{~h}$ and then the mixture was decanted. The process was repeated using a 1:1 propylene oxide/araldite resin mixture. Finally, the 3:1 propylene oxide/araldite resin mixture was added to the cells and the sample was polymerized in a hot air oven at $45^{\circ} \mathrm{C}$ for 2 days, and then at $60^{\circ} \mathrm{C}$ for another 2 days. The embedding process was prepared by transferring the sample into a mold and pure araldite resin was added. The embedded sample was further incubated in a hot air oven at $60^{\circ} \mathrm{C}$ for 2 days. Finally, ultrathin sections were cut from the cell samples at a thickness of $60-90 \mathrm{~nm}$ and observed by TEM (268 Morgagni, Thermofisher, The Netherlands) at $80 \mathrm{kV}$.

\subsection{Statistical analysis}

All experimental data are expressed as a mean \pm standard error (SE). The data were analyzed by using one-way analysis of variance (ANOVA) and Tukey's multiple comparison test in GraphPad Prism ${ }^{\circledast}$ version 6. The significance of statistical data was calculated at $p<0.01$. 


\section{Results and discussion}

\subsection{Characterization of SD-AuNPs}

TEM characterization of the morphology and core size of SD-AuNPs revealed that their morphology was spherical shape (Fig. 1a) and their sizes were not uniform, varying from $\sim 8$ to $58 \mathrm{~nm}$. The majority of the particles $(\sim 53.7 \%)$ had a diameter of $\sim 14.2 \pm 0.1 \mathrm{~nm}$. Approximately $30.1 \%$ of the SD-AuNPs had a diameter of $\sim 8.0 \pm 0.1 \mathrm{~nm}$, and $10.2 \%$ of the population had a diameter of $\sim 24.0 \pm 0.1 \mathrm{~nm}$. Large particles $\sim 33.6 \mathrm{~nm}$ $(5.2 \%), 41.4 \mathrm{~nm}(0.7 \%)$, and $58.1 \mathrm{~nm}(0.1 \%)$ were also detected. The hydrodynamic diameters of SD-AuNPs were $\sim 73 \mathrm{~nm}$ (both in original dietary supplement drink and dispersed in Milli-Q water) and $\sim 64.5 \mathrm{~nm}$ (in cell culture media; Fig. S1 in Supporting Information). Only one plasmon resonance peak was detected, and it had a maximum light absorption peak at $\sim 523 \mathrm{~nm}$ (Fig. 1b). When SD-AuNPs were dispersed in cell culture media, a very small redshift $(\sim 1 \mathrm{~nm})$ of a maximum light absorption was detected. The zeta potentials of SD-AuNPs were also investigated. The zeta potential of the SD-AuNPs was - $24.1 \mathrm{mV}$. According to the label information on the dietary supplement drink, the mass concentration of gold contained in the drink is $10 \mu \mathrm{g} / \mathrm{mL}$. To confirm the amount of gold in this dietary supplement drink, we analyzed the gold content using ICP-MS and found that the content of gold was $9.2 \pm 0.6 \mu \mathrm{g} / \mathrm{mL}$. This mass concentration was in agreement with the gold amount indicated on the label of the representative dietary supplement drink. When the original dietary supplement drink was diluted with Milli-Q water to a mass, concentration of $0.2 \mu \mathrm{g} / \mathrm{mL}$ SD-AuNPs, we found that the zeta potential was $\sim-25.1 \mathrm{mV}$. This indicates that Milli-Q water had no impact on changing the zeta potential of SD-AuNPs. However, when SD-AuNPs at the same concentration were dispersed in cell culture media, the zeta potential
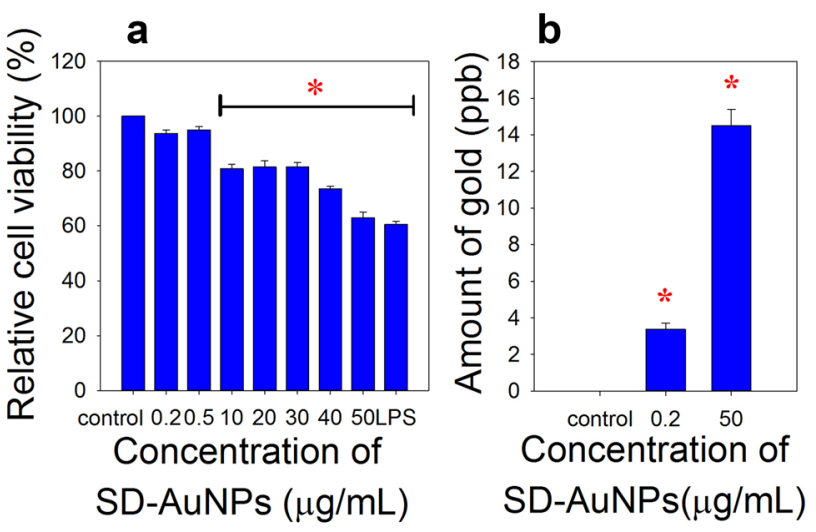

Fig. 2 a Cell viability of L929 cells treated with SD-AuNPs at concentrations of $0.2,0.5,10,20,30,40$, and $50 \mu \mathrm{g} / \mathrm{mL}$ for $24 \mathrm{~h}$ and $\mathbf{b}$ the amount of SD-AuNPs (measured by ICP-MS) associated with L929 cells treated with SD-AuNPs at concentrations of 0.2 and $50 \mu \mathrm{g} / \mathrm{mL}$ for $24 \mathrm{~h}$. Controls were untreated cells in media. For cell viability measurements, cells treated with $1 \mu \mathrm{g} / \mathrm{mL}$ LPS were used as positive controls. The asterisks denote significant differences $(p<0.01 ; \mathrm{n} \geq 8)$ for cell viability measurements and $(p<0.01 ; \mathrm{n} \geq 3)$ for cellular uptake measurements)

of AuNPs showed a less negative value $(\sim-6.0 \mathrm{mV})$. This change is in accordance with many reports $[14,15]$. The reason for the change of zeta potential could be because of the strong ionic strength of the media, which contains organic salts, amino acids, proteins, and vitamins [16, 17].

\subsection{Cell viability and cellular uptake of SD-AuNPs}

Following characterization, the viability of L929 cells treated with SD-AuNPs was investigated. L929 cells were incubated with different concentrations $(0.2-50 \mu \mathrm{g} / \mathrm{mL})$ of SD-AuNPs for $24 \mathrm{~h}$. The viability of L929 cells treated with 0.2 and $0.5 \mu \mathrm{g} / \mathrm{mL}$ was $\sim 91.5 \%$ and $92.9 \%$, respectively. At higher concentrations, in the range of $10-50 \mu \mathrm{g} / \mathrm{mL}$, the viability significantly decreased in a dose-dependent manner to $80.8 \%$ (10 $\mu \mathrm{g} / \mathrm{mL}), 81.5 \%(20 \mu \mathrm{g} / \mathrm{mL}), 81.4 \%$
Fig. 1 Characterizations of SD-AuNPs. a TEM image of SDAuNPs and $\mathbf{b}$ the absorption spectrum of SD-AuNPs a

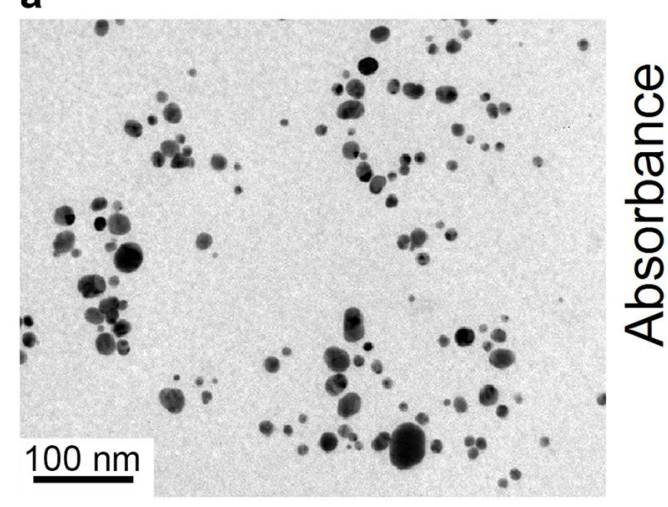

b

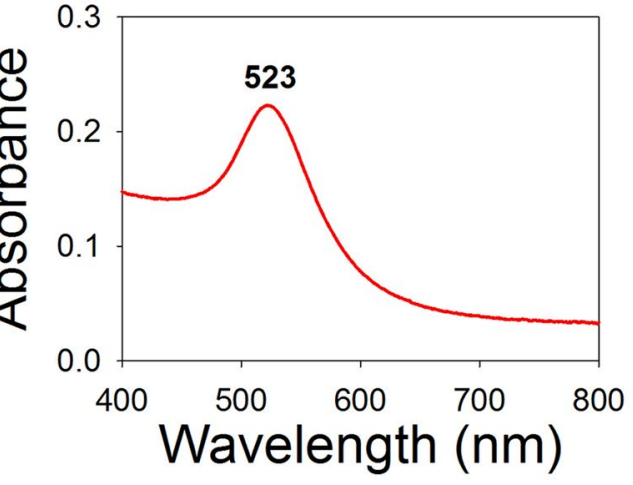


(30 $\mu \mathrm{g} / \mathrm{mL}), 73.5 \%(40 \mu \mathrm{g} / \mathrm{mL})$, and $63 \%(50 \mu \mathrm{g} / \mathrm{mL})$ as compared to untreated cells (Fig. 2a). Cells treated with LPS $(1 \mu \mathrm{g} / \mathrm{mL}$ ) had the lowest cell viability (60.5\%). Greater concentrations of SD-AuNPs likely lead to a higher degree of interaction between the AuNPs and cells which could cause more cellular internalization of SD-AuNPs. To test this hypothesis, the cellular uptake or cellular interaction of AuNPs at a low concentration $(0.2 \mu \mathrm{g} / \mathrm{mL})$ and high concentration $(50 \mu \mathrm{g} / \mathrm{mL})$ was investigated. The results from ICP-MS showed that L929 cells treated with $0.2 \mu \mathrm{g} / \mathrm{mL}$ SDAuNPs for $24 \mathrm{~h}$ had a gold concentration of $\sim 3.4 \pm 0.3 \mu \mathrm{g} / \mathrm{L}$. A much higher gold content $(14.5 \pm 0.9 \mu \mathrm{g} / \mathrm{L})$ was detected in L929 cells treated with $50 \mu \mathrm{g} / \mathrm{mL}$ SD-AuNPs as shown in Fig. 2b. This implies that association and cellular uptake of SD-AuNPs was dependent on the concentration of AuNPs. It was reported that high concentrations of AuNPs in a solution could increase the chance of AuNPs rapidly interacting with cellular receptors, resulting in greater cellular uptake activity than cells treated with low concentration AuNPs [18].

ICP-MS can only provide information on the amount of SD-AuNPs associated with the cells, and does not distinguish between surface bound AuNPs and internalized AuNPs. TEM analysis was performed to see whether SDAuNPs can translocate into cells, and examine the intracellular distribution of the AuNPs. As expected, no SD-AuNPs were detected in control cells (untreated; Fig. 3a). In the case of L929 cells treated with $0.2 \mu \mathrm{g} / \mathrm{mL}$ SD-AuNPs, internalized SD-AuNPs were detected (Fig. 3b). The clusters of SD-AuNPs detected in this treatment were not many. However, L929 cells treated with $50 \mu \mathrm{g} / \mathrm{mL}$ showed many large clusters of internalized SD-AuNPs (Fig. 3c). These results, from ICP-MS and TEM imaging confirm that the concentration of SD-AuNPs directly impacted cellular uptake. As shown in Fig. 3c, a high number of SD-AuNPs accumulated inside the cells and formed a large group of SD-AuNPs. This cluster formation by the SD-AuNPs could be involved in the observed reduction of cell viability. It was reported by Wang et al. [19] that higher doses of AuNPs could result in a higher density and higher propensity towards aggregation of AuNPs inside cells. This could lead to a greater reduction of cell viability. Other studies have also reported a similar impact of the dose of AuNPs on their cluster forming ability and its correlation with the induction of cytotoxicity $[20,21]$.

\subsection{Reactive oxygen species (ROS) generation}

Although it is commonly believed that gold is chemically inert, many studies have shown that the surface properties of AuNPs could impact ROS induction [22-25]. However, this induction might be dependent on the concentration of the AuNPs. For this reason, it was important to
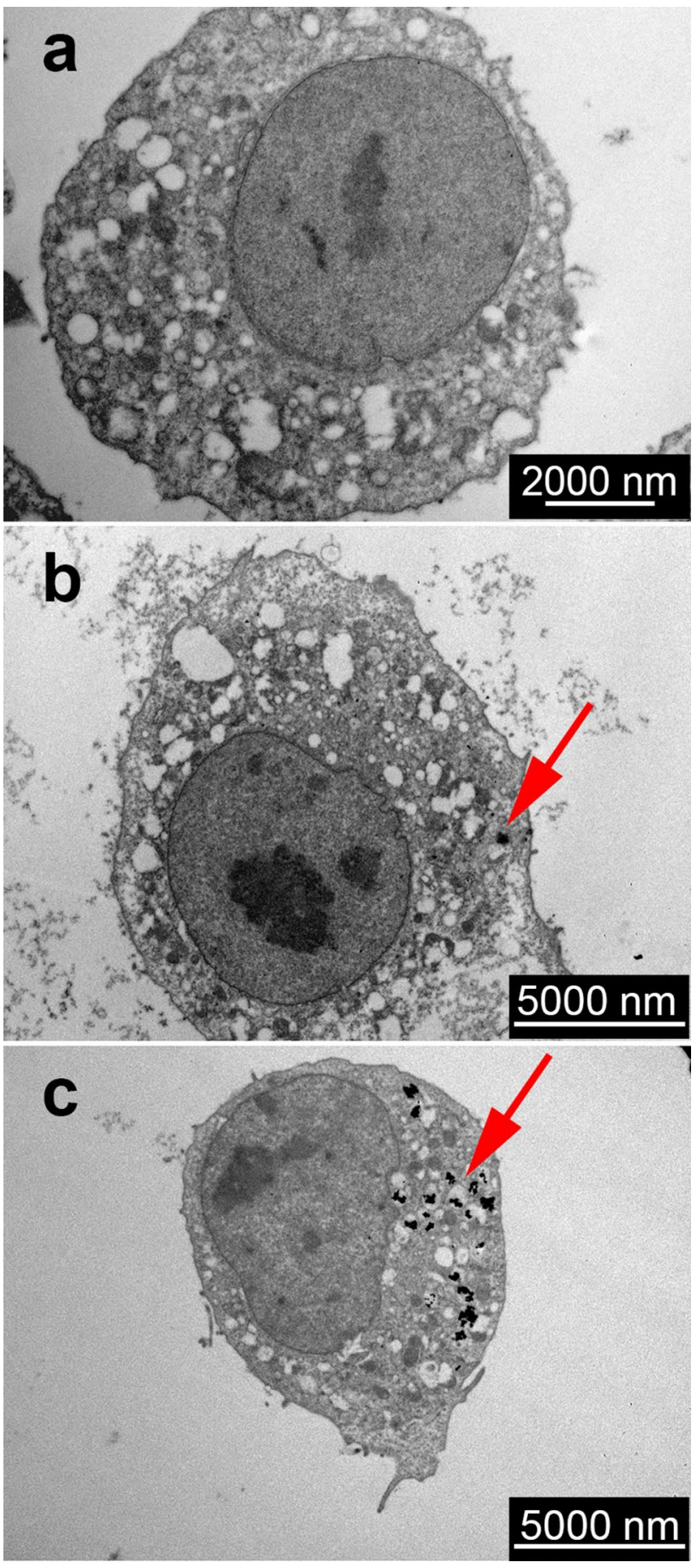

Fig. 3 TEM images of a untreated L929 cells, b L929 cells treated with SD-AuNPs at $0.2 \mu \mathrm{g} / \mathrm{mL}$ and c $50 \mu \mathrm{g} / \mathrm{mL}$ for $24 \mathrm{~h}$. The arrow indicates black dots of SD-AuNPs

investigate whether different concentrations of SD-AuNPs could induce ROS production. We found that L929 cells treated with 40 and $50 \mu \mathrm{g} / \mathrm{mL}$ SD-AuNPs for $3 \mathrm{~h}$ significantly induced ROS production (Fig. 4). As expected, a significant induction of ROS was detected in L929 cells 


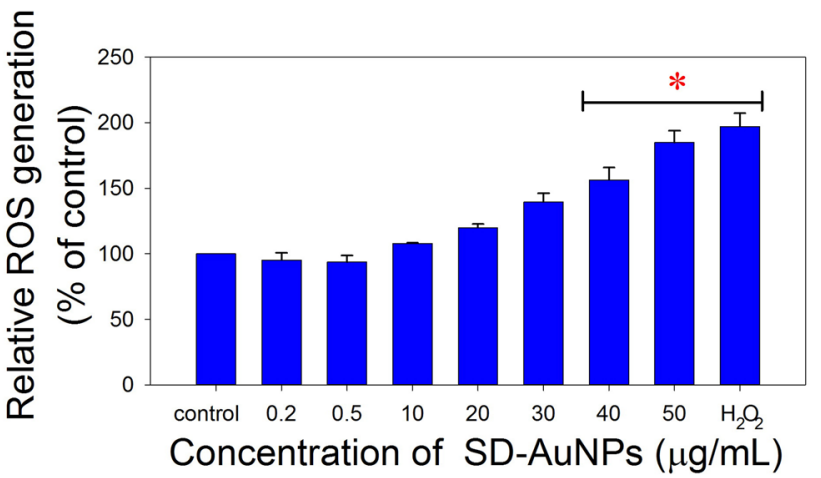

Fig. 4 ROS generation by $L 929$ cells treated with SD-AuNPs at different concentrations $(0.2,0.5,10,20,30,40$, and $50 \mu \mathrm{g} / \mathrm{mL})$ for $3 \mathrm{~h}$. Untreated cells were prepared as controls, and cells treated with $50 \mathrm{mM} \mathrm{H} \mathrm{O}_{2}$ were used as a positive control sample. The asterisks denotes significant differences $(p<0.01 ; n \geq 3)$

treated with $50 \mathrm{mM} \mathrm{H}_{2} \mathrm{O}_{2}$ (a positive control cell). A recent work published by Chaves et al. [26] also demonstrated that at a higher concentration, AuNPs could induce a higher concentration of ROS production at earlier time points. The enhancement of this ROS generation by AuNPs could lead to different pathological events involved in cell death. The size of the AuNPs also has an impact on the induction of ROS. It was reported that AuNPs of $30 \mathrm{~nm}$ could induce more ROS generation than the smaller AuNPs [27]. From TEM images, the sizes of the SD-AuNPs was nonuniform, which might lead to different degrees of interaction between the AuNPs and the cellular membrane of the L929 cells, resulting in different degrees of ROS generation that could impact cell death [28]. Although the current study only focused on the impact of SD-AuNPs on the induction of cytotoxicity, without extensive investigation of the surface properties of commercial SD-AuNPs, it is important to note that besides the size and concentration of AuNPs, the surface property of AuNPs plays a major role in ROS induction as reported by Iswarya et al. [29]. However, a significant induction of ROS was not detected when cells were treated with lower concentrations of SD-AuNPs $(10,20$, and $30 \mu \mathrm{g} / \mathrm{mL})$. This implies that the significant reduction of cell viability at these three concentrations is unlikely to be related to oxidative stress.

\subsection{Inflammatory cytokine response}

It is well known that inflammatory cytokines have an impact on cellular activities such as cell growth and differentiation, as well as on the stimulation of cellular functions [30]. TNF- $\alpha$, IL-6, and IL-1 $\beta$ play a major role in immune dysfunction and in the inflammatory response [31-33]. Therefore, we examined the impact of SD-AuNPs on the induction of these three inflammatory cytokines in L929

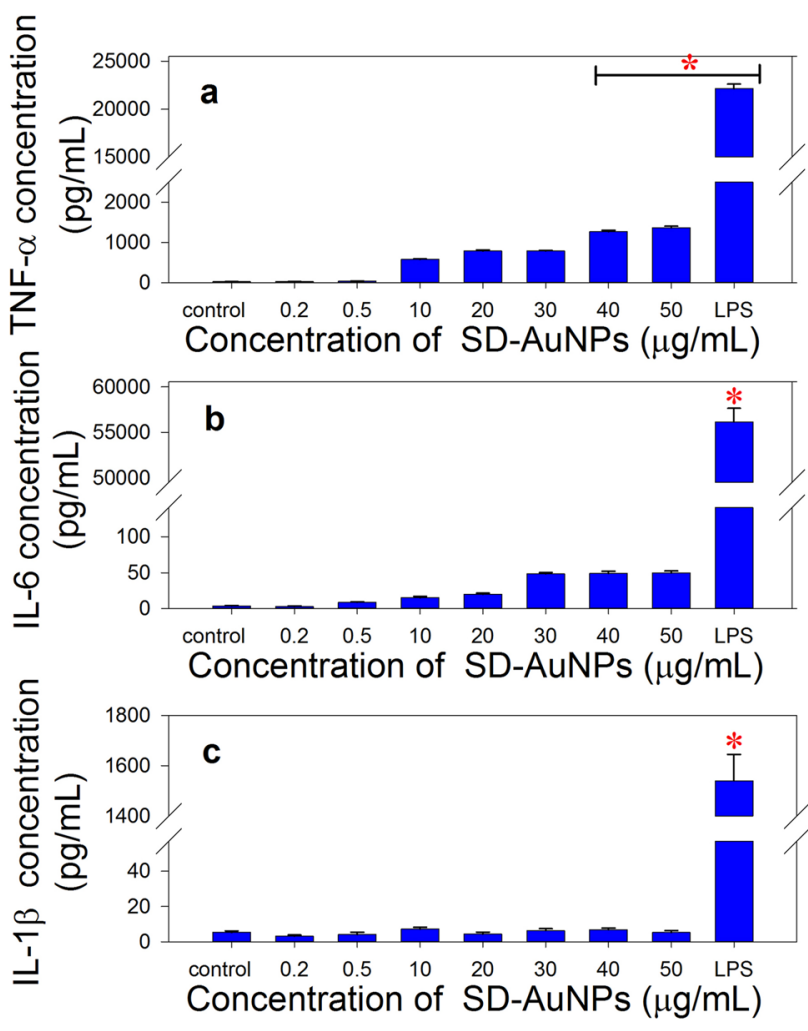

Fig. 5 Pro-inflammatory cytokine responses; a TNF- $\mathbf{a}$, b IL-6, and c IL-1 $\beta$; secreted by $L 929$ cells treated with SD-AuNPs at concentrations of $0.2,0.5,10,20,30,40$, and $50 \mu \mathrm{g} / \mathrm{mL}$ for $24 \mathrm{~h}$. Untreated cells were used as control cells and cells treated with $1 \mu \mathrm{g} / \mathrm{mL}$ LPS were used as positive control cells. The asterisks denotes significant differences $(p<0.01 ; \mathrm{n} \geq 8)$

cells. After cells were treated with different concentrations of SD-AuNPs for $24 \mathrm{~h}$, we found that significant induction of TNF-a was only detected in cells treated with SD-AuNPs at concentrations of 40 and $50 \mu \mathrm{g} / \mathrm{mL}$ SD-AuNPs $(p<0.01)$ (Fig. 5a). Our results show that significant induction of ROS and TNF- a occurred at the same concentrations. This suggests that there might be a related mechanism between the production of these molecules. It was reported that the ROS generated by nanoparticles could lead to induction of TNF-a [34]. According to our previous publication [35], an increase in TNF- a could be involved in stimulating cell death. It has also been reported that TNF-a could lead to the death of fibroblasts [36]. Furthermore, the study by Cheng et al. [37] revealed that TNF-a could induce apoptotic and autophagic cell death in L929 cells. Therefore, it is very important that consumer's attention should be drawn to the concentration of SD-AuNPs. Insignificant increases of IL -6 from $\sim 3.8 \mathrm{pg} / \mathrm{mL}$ (non-treated cells) to $\sim 50 \mathrm{pg} / \mathrm{mL}$ in L929 cells treated with 30,45 , and $50 \mu \mathrm{g} / \mathrm{mL}$ SD-AuNPs were detected (Fig. 5b). The small amounts of secreted IL-6 by cells treated with $0.2,0.5,10$, and $20 \mu \mathrm{g} / \mathrm{mL}$ SD-AuNPs were $~ 3.0,8.9,15.4$, and $20.1 \mathrm{pg} / \mathrm{mL}$ respectively. IL-6 also 
plays an important role in host defense due to its ability to activate acute inflammation [38]. Although there was no significant induction of IL- 6 , the trend of an increased level of IL- 6 when the concentration of SD-AuNPs was elevated, should be of concern. The amounts of IL-1 $\beta$ in L929 cells treated with different concentrations of SD-AuNPs and non-treated cells were similar (Fig. 5c). This implies that SD-AuNPs at the tested concentrations here had no effect on IL-1 $\beta$ induction in L929 cells. As expected, the positive control, L929 cells treated with LPS had high level of all three inflammatory cytokines.

\section{Conclusion}

We have demonstrated the impact of SD-AuNPs in a commercial supplement drink on L929 cells. The cytotoxic impact of SD-AuNPs on L929 cells is highly dependent on concentration. Although AuNPs have been applied in many biological applications, it is important to be aware of their toxicity. Our results provide information that although the product is sold in the form of a supplement drink, consumers still need to pay strong attention to the consumption dose (the suggested dose of this SD-AuNPs is $\sim 0.2 \mu \mathrm{g} / \mathrm{mL}$ ) to avoid any adverse effects that may occur with ingestion.

Acknowledgements This work received major funding support from the Capability Building Unit for Nanoscience and Nanotechnology, Faculty of Science, Mahidol University. The authors thank the Center of Excellence on Environmental Health and Toxicology (EHT), Toxicology and Materials Science and Engineering Programs, Center of Nanoimaging (CNI), and Prof. Piyarat Govitrapong at Faculty of Science, Mahidol University for supporting some facilities used in this work. The authors also thank minor funding support from the Development and Promotion for Science and Technology talents project (DPST). Furthermore, the authors are thankful for the extra funding from the Faculty of Science to support this work. Finally, the authors thank Dr. Sujin Jiracheewanun and Mr. Preecha Sowanthip for their technical support.

\section{Compliance with ethical standards}

Conflict of interest On behalf of all authors, the corresponding author states that there is no conflict of interest.

\section{References}

1. Dykman L, Khelbstov N (2012) Gold nanoparticles in biomedical applications: recent advances and perspectives. Chem Soc Rev 41:2256-2282

2. Pissuwan D, Niidome T, Cortie MB (2011) The forthcoming applications of gold nanoparticles in drug and gene delivery systems. J Control Release 149:65-71
3. Pissuwan D, Valenzuela SM, Cortie MB (2006) Therapeutic possibilities of plasmonically heated gold nanoparticles. Trends Biotechnol 24:62-67

4. Frohlich E, Roblegg E (2012) Models for oral uptake of nanoparticles in consumer products. Toxicology 291:10-17

5. Coradeghini R, Gioria S, Garcia CP, Nativo P, Franchini F, Gilliland D, Ponti J, Rossi F (2013) Size-dependent toxicity and cell interaction mechanisms of gold nanoparticles on mouse fibroblasts. Toxicol Lett 217:205-216

6. Jo MR, Bae SH, Go MR, Kim HJ, Hwang YG, Choi SJ (2015) Toxicity and biokinetics of colloidal gold nanoparticles. Nanomaterials 5:835-850

7. Sung JH, Ji JH, Park JD, Song MY, Song KS, Ryu HR, Yoon JU, Jeon KS, Jeong J, Han BH, Chung YH, Chang HK, Lee JH, Kim DW, Kelman BJ, Yu IJ (2011) Subchronic inhalation toxicity of gold nanoparticles. Part Fibre Toxicol 8:16

8. Ravensthorpe M (2013) Colloidal gold: the great rejuvenator of mind and body. IOP Publishihing Natural News Web. https ://thezeitgeistindia.blogspot.com/2013/12/new-post-three -beneficial-colloids-and.html. Accessed 19 Dec 2013

9. Chaves CA, Vergani CE, Thomas D, Young A, Costa CA, Salih VM, Machado AL (2014) Biological effects of soft denture reline materials on L929 cells in vitro. J Tissue Eng 5:1-8

10. Hashimoto M, Yamaguchi S, Sasaki J, Kawai K, Kawakami H, Iwasaki Y, Imazato S (2016) Inhibition of matrix metalloproteinases and toxicity of gold and platinum nanoparticles in L929 fibroblast cells. Eur J Oral Sci 124:68-74

11. Liu X, Tang M, Zhang T, Hu Y, Zhang S, Kong L, Xue Y (2013) Determination of a threshold dose to reduce or eliminate CdTe-induced toxicity in L929 cells by controlling the exposure dose. PLoS ONE 8:59359

12. Miranda RB, Fidel SR, Boller MA (2009) L929 cell response to root perforation repair cements: an in vitro cytotoxicity assay. Braz Dent J 20:22-26

13. Kim C, Agasti SS, Zhu Z, Isaacs L, Rotello VM (2010) Recognition-mediated activation of therapeutic gold nanoparticles inside living cells. Nat Chem 2(11):962-966

14. Foo YY, Periasamy V, Kiew LV, Kumar GG, Malek SNA (2017) Curcuma mangga-mediated synthesis of gold nanoparticles: characterization, stability, cytotoxicity, and blood compatibility. Nanomaterials 7:1

15. Sabuncu AC, Grubbs J, Qian S, Abdel-Fattah TM, Stacey MW, Beskok A (2012) Probing nanoparticle interactions in cell culture media. Colloids Surf B Biointerfaces 95:96-102

16. Moore TL, Rodriguez-Lorenzo L, Hirsch V, Balog S, Urban D, Jud C, Rothen-Rutishauser B, Lattuada M, Petri-Fink A (2015) Nanoparticle colloidal stability in cell culture media and impact on cellular interactions. Chem Soc Rev 44:6287-6305

17. Yallapu MM, Chauhan N, Othman SF, Khalilzad-Sharghi V, Ebeling MC, Khan S, Jaggi M, Chauhan SC (2015) Implications of protein corona on physico-chemical and biological properties of magnetic nanoparticles. Biomaterials 46:1-12

18. Trono JD, Mizuno K, Yusa N, Matsukawa T, Yokoyama K, Uesaka M (2011) Size, concentration and incubation time dependence of gold nanoparticle uptake into pancreas cancer cells and its future application to $x$-ray drug delivery system. J Radiat Res Appl Sci 52:103-109

19. Wang SH, Lee CW, Shen KC, Tseng FG, Wei PK (2015) Dose dependent distribution and aggregation of gold nanoparticles within human lung adeno-carcinoma cells. RSC Adv 5:98309-98317

20. Rayavarapu RG, Petersen W, Hartsuiker L, Chin P, Janssen H, Van Leeuwen FW, Otto C, Manohar S, Van Leeuwen TG (2010) In vitro toxicity studies of polymer-coated gold nanorods. Nanotechnology 21:145101 
21. Yao C, Zhang L, Wang J, He Y, Xin J, Wang S, Xu H, Zhang Z (2016) Gold nanoparticle mediated phototherapy for cancer. J Nanomater 2016:1-26

22. Chompoosor A, Saha K, Ghosh PS, Macarthy DJ, Miranda OR, Zhu ZJ, Arcaro KF, Rotello VM (2010) The role of surface functionality on acute cytotoxicity, ROS generation and DNA damage by cationic gold nanoparticles. Small 6:2246-2249

23. Mateo D, Morales P, Avalos A, Haza Al (2014) Oxidative stress contributes to gold nanoparticle-induced cytotoxicity in human tumor cells. Toxicol Mech Methods 24:161-172

24. Rosa S, Connolly C, Schettino G, Butterworth KT, Prise KM (2017) Biological mechanisms of gold nanoparticle radiosensitization. Cancer Nanotechnol 8(1):2

25. Wahab R, Dwivedi S, Khan F, Mishra YK, Hwang IH, Shin HS, Musarrat J, Al-Khedhairy AA (2014) Statistical analysis of gold nanoparticle-induced oxidative stress and apoptosis in myoblast (C2C12) cells. Colloids Surf B Biointerfaces 123:664-672

26. Chaves LC, Alvaredo SJ, Bayon MM, Bettmer J, Llopis J, Gonzalez SC (2018) Gold nanoparticles: distribution, bioaccumulation and toxicity. In vitro and in vivo studies. Nanomedicine 14(1):1-12

27. Piryazev A, Azizova O, Aseichev A, Dudnik L, Sergienko V (2013) Effect of gold nanoparticles on production of reactive oxygen species by human peripheral blood leukocytes stimulated with opsonized zymosan. Bull Exp Biol Med 156:101-103

28. Wang $P$, Wang $X$, Wang L, Hou X, Liu W, Chen C (2015) Interaction of gold nanoparticles with proteins and cells. Sci Technol Adv Mater 16:034610

29. Iswarya V, Manivannan J, DeSubhabrata A, Roy P, Johnson JB, Kundu R, Chandrasekaran N, Mukherjee A (2016) Surface capping and size-dependent toxicity of gold nanoparticles on different trophic levels. Environ Sci Pollut Res Int 23:4844-4858

30. Zhang JM, An J (2007) Cytokines, inflammation, and pain. Int Anesthesiol Clin 45(2):27-37

31. Wojdasiewicz P, Poniatowski LA, Szukiewicz D (2014) The role of inflammatory and anti-inflammatory cytokines in the pathogenesis of osteoarthritis. Mediators Inflamm. https://doi. org/10.1155/2014/561459

32. Tackey E, Lipsky P, Illei GG (2004) Rationale for interleukin-6 blockade in systemic lupus erythematosus. Lupus 13(5):339-343

33. Umare V, Pradhan V, Nadkar M, Rajadhyaksha A, Patwardhan M, Ghosh KK, Nadkarni AH (2014) Effect of proinflammatory cytokines (IL-6, TNF-alpha, and IL-1 beta) on clinical manifestations in Indian SLE patients. Mediators Inflamm 2014:385297

34. Matthias R, Cordula H, Jean-Pierre K, Harald FK, Peter W (2013) Comparability of in vitro tests for bioactive nanoparticles: a common assay to detect reactive oxygen species as an example. Int J Mol Sci 14(12):24320-24337

35. Pissuwan D, Kumagai Y, Smith NI (2013) Effect of surface-modified gold nanorods on the inflammatory cytokine response in macrophage cells. Part Part Syst Charact 30:427-433

36. Pastorino JG, Simbula G, Yamamoto K, Glascott PA, Rothman RJ, Farber JL (1996) The cytotoxicity of tumor necrosis factor depends on induction of the mitochondrial permeability transition. J Biol Chem 271:29792

37. Cheng Y, Qiu F, Tashiro SI, Onodera S, Ikejima T (2008) ERK and JNK mediate TNFa-induced p53 activation in apoptotic and autophagic L929 cell death. Biochem Biophys Res Commun 376:483-488

38. Simson RJ, Hammacher A, Smith DK, Matthews JM, Ward LD (1997) Interleukin-6: structure-function relationships. Protein Sci 6:929-955

Publisher's Note Springer Nature remains neutral with regard to jurisdictional claims in published maps and institutional affiliations. 